\title{
Irrigación endodontica con el uso de hipoclorito de sodio
}

Endodontic irrigation with the use of sodium hypochlorite

\section{ARtículo de Revisión}

\author{
Víctor Lahoud Salem ${ }^{1 *}$ y \\ Luis H. Galvéz Calla ${ }^{2^{\star}}$ \\ 1 Departamento Académico de Estomatología \\ Rehabilitadota \\ 2 Departamento Académico de Ciencias Bási- \\ cas \\ * Facultad de Odontología, Universidad \\ Nacional Mayor de San Marcos, Lima, Perú. \\ E-mail: vlahouds@unmsm.edu.pe
}

\section{Resumen}

El presente artículo científico tiene por finalidad resaltar las propiedades del hipoclorito de Sodio, sus características, los agentes que pueden alterarlos y los métodos de irrigación a emplearse en el mismo para obtener resultados satisfactorios.

Palabras clave: irrigación, hipoclorito de Sodio, preparación biomecánica.

\author{
Abstrac \\ The present cientific article is to emphasize the Sodium Hypochlorite property, its \\ characteristic the agents that may alter them and the method of irrigation to use in the \\ to obtain satisfactory results
}

Key words: irrigation, Sodium

hypochlorite, biomechanic preparation

\section{Introducción}

El proceso de irrigación consiste en el lavado y aspiración de todos los restos y sustancias que pueden estar contenidas dentro del sistema de conductos y se lleva a cabo mediante el uso de agentes químicos aislados o combinados (Figs. 1 A y B).

Constituye un paso más en el proceso de limpieza y conformación del sistema de conductos radiculares y último procedimiento antes de realizar la obturación tridimensional de los mismos.

Lasala A. ${ }^{1}$ define el proceso de irrigación como un lavado y aspiración de todos los restos y sustancias que pueden estar contenidos en la cámara pulpar o conductos radiculares siendo uno de los procedimientos más importantes durante la terapia endodóntica.

Finalidades del proceso de irrigación:

- Eliminar restos pulpares, virutas de dentina y restos necróticos que pueden actuar como nichos de bacterias; además estos restos pueden desplazarse a la región periapical produciendo agudizaciones.

- Disminuir la flora bacteriana.

- Humedecer o lubricar las paredes dentinarias facilitando la acción de los instrumentos.
- Eliminar la capa de desecho.

- Aumentar la energía superficial de las paredes del conducto, favoreciendo el contacto de los medicamentos usados como curación temporaria y permitir la retención mecánica de los cementos obturados, Leonardo $\mathrm{M}^{2}$.

Para cumplir con estas finalidades, las soluciones irrigantes deben poseer ciertas propiedades que lo hagan una solución irrigante ideal, estos son:

Solvente de tejidos o desechos

Baja toxicidad

Lubricante

Desinfección

Eliminación de la capa de desecho

Propiedades del Hipoclorito de Sodio (NaOCl)

La Asociación Americana de Endodoncistas $^{3}$ ha definido el Hipoclorito de Sodio como un liquido claro, pálido, verde-amarillento, extremadamente alcalino y con fucrte olor clorino, que presenta una acción disolvente sobre el tejido necrótico y restos orgánicos y además es un potente agente antimicrobiano.

Al Hipoclorito de Sodio se le han atribuido varias propiedades beneficiosas durante la terapia endodóntica (Figs: 2 A y B):
1.- Desbridamiento, la irrigación con Hipoclorito de Sodio expulsa los detritos generados por la preparación biomecánica de los conductos.

2.- Lubricación, humedece las paredes del conducto radicular favoreciendo la acción de los instrumentos.

3.- Por ser un agente antimicrobiano eficaz, destruye y elimina todos los microorganismos de los conductos radiculares, incluyendo virus $y$ bacterias que se forman por esporas, Cohen S. ${ }^{4}$

4.- Disolución de tejidos, es el disolvente más eficaz del tejido pulpar. Una pulpa puede ser disuelta entre 20 minutos a 2 horas. La eficacia de la disolución del Hipoclorito de Sodio depende de la integridad estructural de los componentes del tejido conjuntivo de la pulpa. Si la pulpa está descompuesta, los restos de tejidos se disuclven rápidamente, si esta vital y hay poca degradación estructural, el Hipoclorito de Sodio necesita más liempo para disolver los restos.

El Hipoclorito de Sodio reacciona con residuos orgánicos en cl conducto radicular y de esta forma facilita la limpieza, sin embargo esta reacción inactiva químicamente al $\mathrm{NaOCI}$ y reduce su capacidad antibacteriana, por esto una solución 


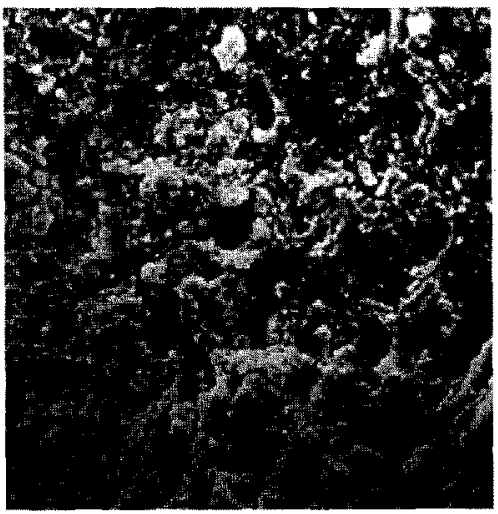

A

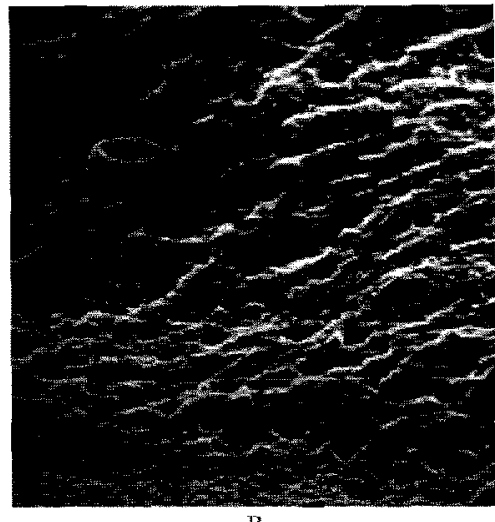

$\mathrm{B}$

Fig.1. A. Conducto radicular que no ha sido tratado con ácido, donde se observan los túbulos obstruidos con detritus. B. Conducto radicular tratado con otra sustancia de uso similar al $\mathrm{NaOCL}$ (ácido cítrico) donde se observa superficie libre de detritus. Tomada de Ingle J. Endodontics. 4ta edición, 1994.
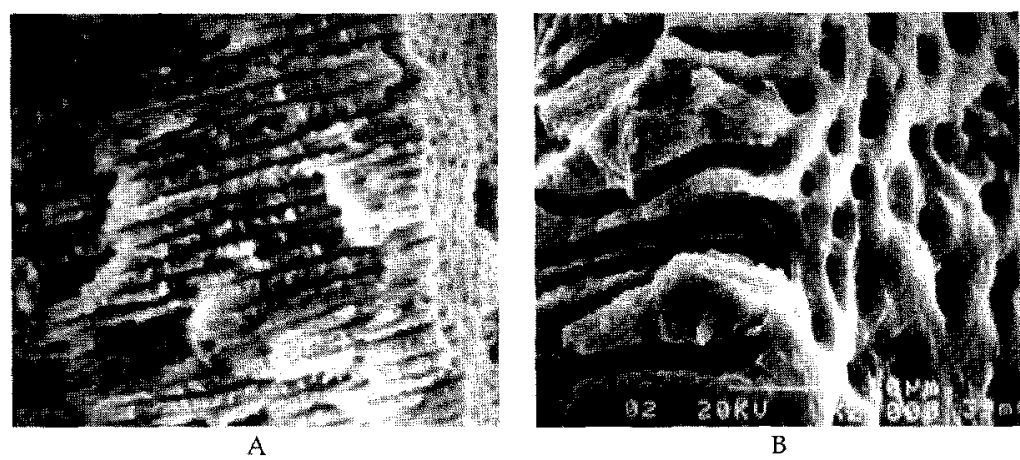

Fig.2. A. SEM fotografía que muestra dos canales laterales y lúbulos irrigados con NaOCl libre de detritos. B. SEM fotografia que muestra conductos irrigados con NaOC caliente, donde se observa mayor limpieza. Tomada de Cohen S. Path ways of the pulp 8 edición. 2002

fresca debe ser aplicada frecuentemente dentro del conducto para reactivar la reacción química y la remisión de restos, Bystrom $A .^{5}$

5.- Baja tensión superficial lo cual permite penetrar a todos las concavidades del conducto radicular, al mismo tiempo que crea las condiciones para la mayor eficiencia del medicamento aplicado de forma tópica. Cuando el lavado final se realizacon Hipoclorito de Sodio, los resultados en cuanto a la remoción de la capa de desecho fueron efectivos Goldman $M^{6}$. Estudio realizado por Mérida $\mathrm{H}^{7}$ se obtuvo como resultado que la capacidad de penetración del Hipoclorito está relacionado con su concentración, cuando se encuentre del $1 \%$ puede penetrar 100 micras a los canalículos dentinarios al $2.5 \%$ penetra 220 micras y al $5.25 \%$ penetra 350 micras.

Factores que afectan las propiedactes del Hipoclorito de Sodio

\section{1.- Efectos de la temperatura}

El aumento de temperatura liene efecto positivo sobre la acción disolvente del
Hipoclorito de Sodio . Temperatura de $35.5^{\circ} \mathrm{C}$ aumenta el poder solvente sobre tejidos necróticos y en tejidos frescos se obtiene el mayor efecto a $60^{\circ} \mathrm{C}$ Gambarini $G^{8}$. Cunninghan $N^{9}$. demostró que el $\mathrm{NaOCL}$ al $5.2 \%$ y $2.6 \%$ eran igualmente eficaces a una temperatura de $37^{\circ} \mathrm{C}$ sin embargo a temperatura ambiente $\left(21^{\circ} \mathrm{C}\right)$ la solución al $2.6 \%$ resultaba menos solución aumenta su efecto bacteriada, pero se debe tener la precaución al calentarlo a $37^{\circ} \mathrm{C}$, ya que se mantiene estable por no más de 4 años antes de degradarse, por lo que no se recomienda recalentar la solución.

\section{2.- Dilución}

Algunos clínicos diluyen el Hipoclorito al $5.25 \%$ para reducir el olor o reducir el potencial de toxicidad a los tejidos periradiculares. La dilución al $5.25 \%$ disminuye en forma significativa la propiedad antimicrobiana, la propiedad de disolución del tejido y la propiedad de desbridamiento del sistema de conductos, Harrison ${ }^{10}$. El Hipoclorito es más eficaz en la disolución de tejido vital desvitalizado y fijado al utilizar en concentraciones eficaz. El calentamiento (Fig. 2 B) de la de $5.25 \%$ que al $2.6 \%$, 1 y $0.5 \%$, Harrison $W .11$

\section{3.- Grado de pureza}

Los Hipoclorito de acuerdo a su pureza química se clasifica de acuerdo a su porcentaje diferencial en; menos puros de 1 a $96 \%$ y más puros de $96-100 \%$ que tiene apenas trazas de contaminantes por lo tanto no es recomendable usar Clorox caseros o domésticos para irrigación durante el tratamiento de conductos, Merida $\mathrm{H}^{7}$.

El Clorox tiene $60 \%$ de pureza y se incluye entre los Hipoclorito de uso industrial y es el recomendado para la terapia endodontica; en otros tienen una pureza de $40-50 \%$ por lo cual se incluyen entre Hipoclorito de uso domestico, estos últimos no son recomendables.

Proceso de irrigación de desechos dentinarios

4. Combinación con otras sustancias (Fig. 3)

La irrigación tiene doble propósitor actúan sobre el componente orgánico removiendo los restos de tejido pulpar y microorganismos presentes y sobre el componente inorgánico para rcmover la capa.

Existen 2 tendencias en una se hace énfasis en las propiedades químicas del agente irrigante y en otra la mayor consistencia en la acción mecánica de la solución como agente de arrastre algunos estudios concluyen que la acción de arrastre es más importante que el tipo de irrigantes y que la acción de limpieza es una función más de la cantidad que del tipo de agente irrigante, Baker $\mathrm{N}^{12}$

La frecuencia de irrigantes y el volumen del irrigante son factores importantes en la remoción de los restos, la frecuencia de irrigantes debe aumentar a medida que la preparación se acerca a la construcción apical un volumen apropiado de el irrigante este por lo menos 1 a $2 \mathrm{ml}$ cada vez que el conducto se irriga, Cohen $\mathrm{S}^{13}$.

Un clave para mejor eficacia del irrigante en la porción apical, es el uso de la lima de recapitulación antes de cada irrigación, ya que en la recapitulación se remueven los restos de dentina y restos compactos en la región apical, hacia la solución pudiendo ser removidos, Cohen $S^{13}$

Entre las técnicas de irrigación unas emplean jeringas plásticas para colocar el irrigante en la cámara pulpar y llevarlo con limas hacia las partes más 


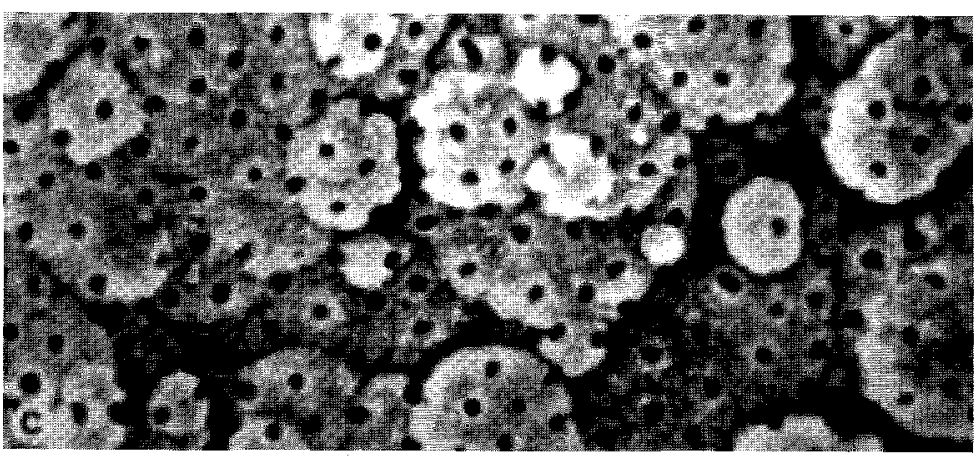

Fig.3. Superficie del conducto radicular vista al microscopio electrónico de barrido tras la irrigación con ácido cítrico al $6 \%$ combinado con $\mathrm{NaOCl}$ al $2 \%$. Tomada de Beer $\mathrm{R}$. Atlas de endodoncia, 1998.

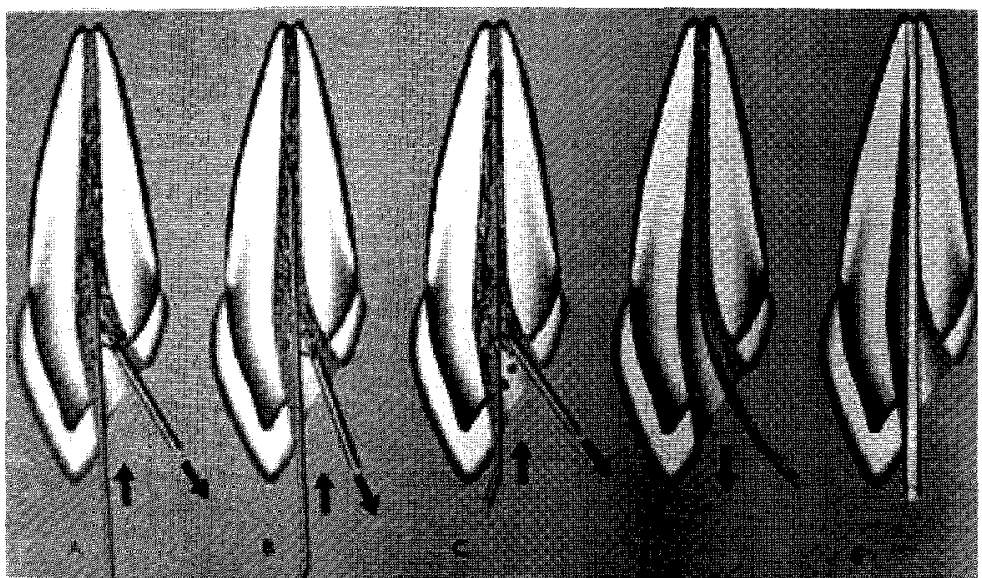

Fig. 4. Pasos de una correcta irrigación de conductos. Tomada de Goldberg F. Endodoncia Técnica y fundamentos.2002.

profundas. Otras usan agujas de anestesia o agujas perforadas, Abbott $\mathrm{P} .{ }^{14}$

En cuando a las agujas o más importantes es el calibre que debe ser pequeño, se prefiere la aguja calibre 27 , que posee el potencial de penetración con mayor profundidad en el conducto.

Una aguja de menor calibre en combinación en el ensanchamiento de conductos y la irrigación frecuentes y abundante permitirá un lavado apropiado.

La efectividad de la irriganción en la porción apical esta relacionada en la profundidad de inserción de la aguja, por lo tanto se debe seleccionar la aguja de acuerdo al tamaño del conducto Radicular, Ghowt. ${ }^{15}$

Se puede utilizar los conos de papel absorbentes calibrados, humedecidos en el liquido irrigador seleccionado. El cono de papel absorbente al humedecerse aumenta su tamaño en un 60 a $80 \%$ ejerciendo una presión lateral, que complementado con un movimiento de vaivén englobe los restos y deja las paredes del conducto limpias en su totalidad, Lasala. ${ }^{1}$

En cuanto a la técnica, la aguja no debe quedar ajustada dentro de las paredes del conducto, debe aplicarse un movimiento de bombco reduciendo al mínimo el peligro de impulsar el irrigante hacia los tejidos periradiculares (Fig. 4).

\section{Conclusiones}

El I lipoclorito de Sodio logra efectivos resultados en la remosión del tejido pulpar. Por el contrario su acción sobre el tejido inorgánico ha mostrado ser poco convincente.

El aumento de la temperatura del Hipoclorito de Sodio, aumenta el efecto bactericida, la capacidad disolutoria del tejido y mejora el desbridamiento sin afectar la estabilidad química de la solución, aunque sólo se mantiene estable por 4 horas.

La dilución del Hipoclorito de Sodio al $5.25 \%$ disminuye las propiedades antimicrobianas, disolutorias del tejido y de desbridamiento del sistema de conducto.

La efectividad de un método irrigante está directamente relacionada con la capacidad de remosión del tejido or- gánico e inorgánico, la frecuencia , el volumen empleado, la temperatura y la cercanía a la constricción apical.

\section{Referencias}

1. Lasala A. Endodoncia 1993.4ta ed. México, Salvat.

2. Leonardo M. Preparación biomecánica de los conductos radiculares, medios fisicos: irrigación, aspiración einundación. Endodoncia tratamiento de los conductos radiculares. Argentina, Editorial Médica Panamericana,1994:268-75.

3. Glossary: American Association of Endodontics. Contemporary terminology for Endodontics. 6th ed. Chicago, 1998.

4. Cohen S, Burns RC. Pathways of the pulp 1998. Missouri. Mosby

5. Byström $A$. The antibacterial action of sodium hypoclorite and EDTA in 60 cases of endodontic therapy. Int Endod J 1985; 18:35-40.

6. Goldman M. The efficacy of several endodontic irrigating solutions: a scanning electron microscopic study: part 2. J Endodon 1982; 11:487-92.

7. Mérida H. Estudio con microscopio electrónico de barrido de la acción desinfectante de diez diferentes irrigantes sobre los conductos dentinarios. V Interamerican Electrón Microscopy Congress,1999, Porlamar, Isla de Margarita

8. Gambarini G. Quemical stability of heated sodium hypoclorite endodontic irrigant. J Endodon 1998; 24: 432-4.

9. Cunninghan W. Effect of temperature on the bactericidal action of sodium hypoclorite endodontic irrigant. Oral Surg 1980; 50:569.

10. Harrison. Irrigation of the root canal system. DentClin North Am 1984;28:797808.

11. Harrison $W$. The effect of dilution and organic matter on the antibacterial property of $5,25 \%$ sodium hypoclorite. J Endodon $1981 ; 7: 128$

12. Baker N. Scanning electron microscopic study of the efficacy of various irrigating solution. J Fndodon 1975; 1:127-31.

13. CohenS, Burns RC. Pathways of the pulp 1994. Missouri. Mosby

14. AbbottP. An SEM study of the effects of different irrigation sequences and ultrasonics. Int. Endod. J. 1991; 24:308-16.

15. Ghowt $W$. Mechanical effectiveness of root canal irrigation. I Endodon 1983; 9(11)475-79.

* Fragmentos del articulo presente han sido reproducido del trabajo "Lná visión actualizada del uso del Hipoclorito de Sodio en Endodoncia" por Edna Jaquez Bairan \& Maite Marcano Caidera. 